ISAHP 2009 Symposium, July 29-August 1, 2009, Pittsburgh, Pennsylvania, USA

\title{
EVALUATION OF THE MAJOR CRITERIA INTENSITIES FOR IRANIAN PARTICLEBOARD PRODUCTS WITH RESPECT TO MANUFACTURER'S ASPECTS
}

\author{
Majid Azizi* \\ Associate professor, Faculty of Natural Resources \\ University of Tehran \\ Karaj, Tehran, IRAN \\ Email: mazizi@ut.ac.ir \\ Alireza Khakifirooz \\ Manager of cellulosic and packaging research group of ISIRI \\ (Institute of standards and industrial research of Iran) \\ Karaj, Tehran, IRAN \\ Farimah Moghimi \\ Graduate student, Faculty of Natural Resources \\ University of Tehran \\ Karaj, Tehran, IRAN
}

\begin{abstract}
Kinds of the particleboards are produced in Iran. The products are different together with respect to some physical and mechanical criteria, also quality and quantity of the production is growing. Successful competition of the products will need to acknowledge criteria intensities of the products. There are five major criteria which have influence on particleboard products ranking, including, moisture percent; density; thickness swilling percent; water absorption percent and bending strength. Three levels of the criteria intensities have been evaluated: high (H), medium (M) and low (L). AHP and Expert Choice 2000 have been used to evaluate weighing values of particleboards criteria and their intensities with respect to manufacturer's aspects. The results indicated that density of the products and its high intensity has the highest priority.
\end{abstract}

Key words: particleboard, intensity, criteria, AHP

\section{Introduction}

Evaluation of wood panel products quality to develop of them is very important factor. Consideration of standard criteria for these products leads to reach high quality and resistance for the products. Particleboard product is a major panel product in Iran.

With respect to the statistics of formal organizations the production of the panel is fast growing in past decade from $380000 \mathrm{~m}^{3}$ to $720000 \mathrm{~m}^{3}$. Increasing past decade consumption in particleboard leads to consider quality specifications of the panel product. In European countries 40 percent in particleboard product is applied in construction panels. Consideration in physical and mechanical specifications of particleboard will improve humidity and climate resistance and water absorption of the product. For acknowledgement of effective criteria which effect on specification of

\footnotetext{
* Corresponding author
} 
particleboard product we selected 5 of them with respect to experts of Institute of standards and industrial research of Iran. The attributes considered most relevant from the expert's aspects are (1) moisture percent, (2) density, (3) thickness swilling percent (4) water absorption percent, (5) bending strength. Institute of standards and industrial research of Iran in number of 2496 consider national standard for 16 millimeter thickness particleboard (Cellulose and packaging research group, 2002). In subsection of this part, numbers of 814, 813, 2489, 2488 and 2332 are related to moisture percent; density; thickness swilling percent; water absorption percent and bending strength respectively. Specification of the criteria has been showed in Table 1. Three levels of intensities have been evaluated: high (H), medium (M) and low (L). AHP has been applied to determine effective criteria weighing values and their intensities.

This method was first invented by Thomas L. Saaty in 1970s, and it is used in decision making processes which have qualitative and quantitative criteria (Saaty, 2000). Effective criteria of Iranian facial tissue determined with respect to consumer perspective by using AHP, the results indicated softness criterion has highest priority (Azizi, 2007). Azizi et al. (2003) used AHP to determine effective criteria for location selection of plywood and veneer units. They identified 25 criteria and sub-criteria in this research. Azizi (2008) applied AHP to determine non development criteria for Iranian particle board industry. Chen and Li (2001) state in their paper that AHP is useful in making business decisions, such as the evaluation of alternative marketing strategies, the choice of candidates for jobs. Comments and discussions regarding the AHP method are also provided.

\section{Materials and Methods}

The criteria which are influence on specifications of particleboard products are as follows:

1. Moisture percent: with respect to standard number 814 , precision of measurement to determine moisture percent of the product is 0.1 percent and range of the moisture is $0.6-0.8$ percent. Moisture content has been calculated via moisture content's arithmetical means of all of the related test samples.

2. Density: with respect to standard number 813 density measurement range of the product is $0.6-0.8 \mathrm{~g} / \mathrm{cm}^{2}$. Precision of density measurement is $0.01 \mathrm{~g} / \mathrm{cm}^{2}$

3. Thickness swilling percent: according to standard number 2489, with based on floatation of the sample in water $20 \pm 2$ temperature and dimension of the sample $100 * 200 \mathrm{~mm}^{2}$, variation of the thickness is 12 percent after 2 hour floating.

4. Water absorption percent: according to standard number 2488, with based on floatation of the sample in distilled water $20 \pm 2$ temperature, after 2 hour, the weight of the water absorption percent with relation to dry position is measured. According to standard water absorption percent is 50 percent.

5. Bending strength: according to standard number 2332, bending strength is measured and limitation of the strength $160 \mathrm{~kg} / \mathrm{cm}^{2}$ is defined.

\subsection{Preparation of the questionnaire}

We did interviews with the manufacturers and product experts and were collected information in Institute of standards and industrial research of Iran. Then with respect to manufacturers aspects 5 criteria were recognized which are effective on the product. After the hierarchy of these criteria was drawn up, a questionnaire was distributed among the experts from university, producers and Institute of standards and industrial research as a two-by-two 
comparison between criteria and sub-criteria to determine the weighting value rate these criteria influence on the product.

\subsection{Analytical Hierarchy Process}

AHP is a method for decision-making by which we can make some decisions which are dependant on several criteria or multi-criteria decisions. By AHP method, first the given structure and then the criteria relevant to decision making are compared to each other and then the priority rate of each one are determined. Numbers which are used in two-by-two comparison are from $1 \div 9$ to 9 which is in the form of a standard scale (Saaty, 2000). Application of AHP is based on the following three principles (Asgharpoor, 1999): A) Establishment of a structure and a rank-based from for the problem. B) Establishment of preferences by two-by-two comparison. C) Establishment of logical consistency from measurement. The AHP is basically a simple, efficient technique for problem solving. The resulting hierarchy is shown in Figure 1.

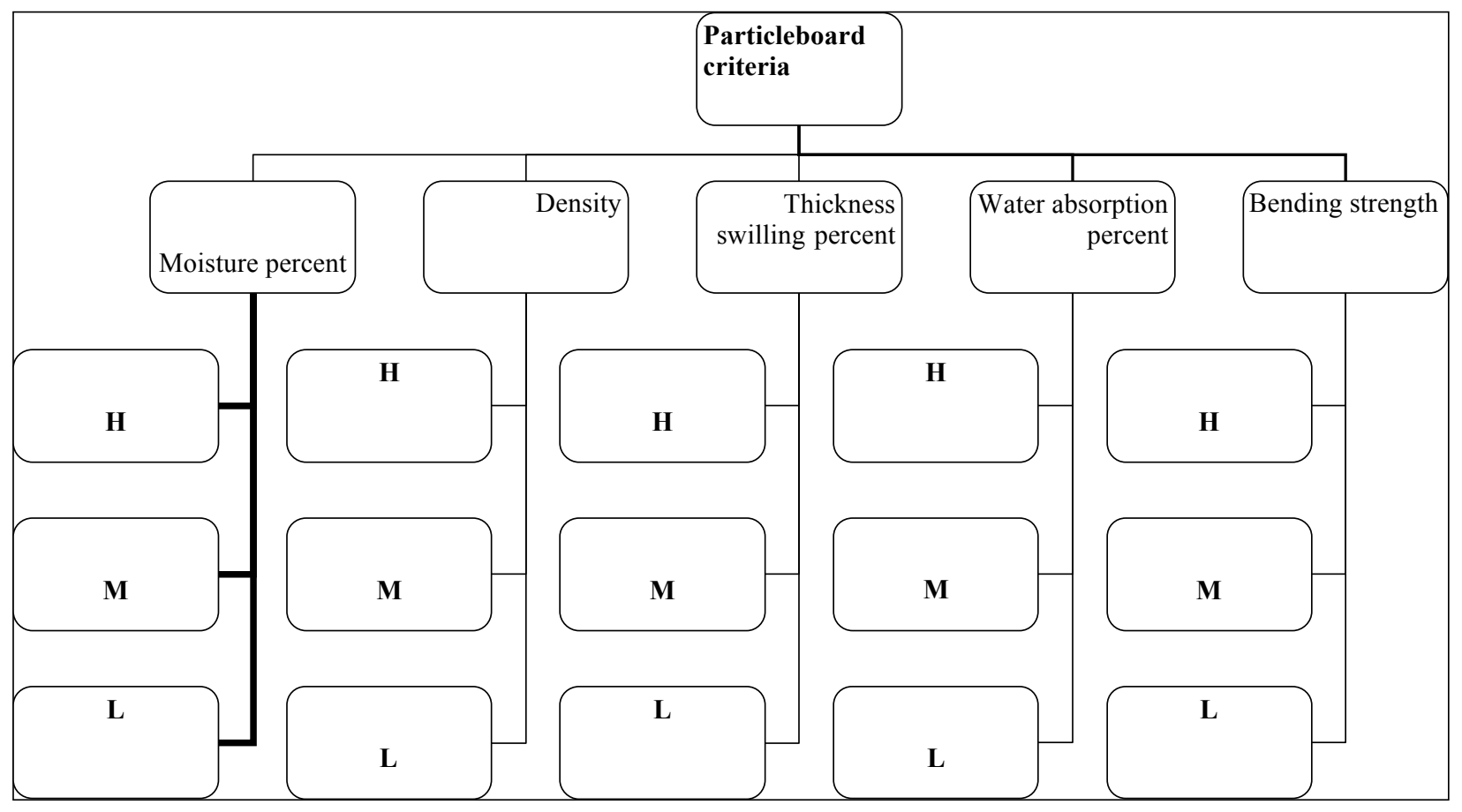

Figure 1: Hierarchy of effective criteria for particleboard product

\section{Results}

Weighting value of the effective criteria and sub-criteria for the particleboard plus geometric mean of comparison matrices is put forward here as results of group decision making by a group of the experts with the aid of Expert Choice Software (Figures 2-9, table1). 


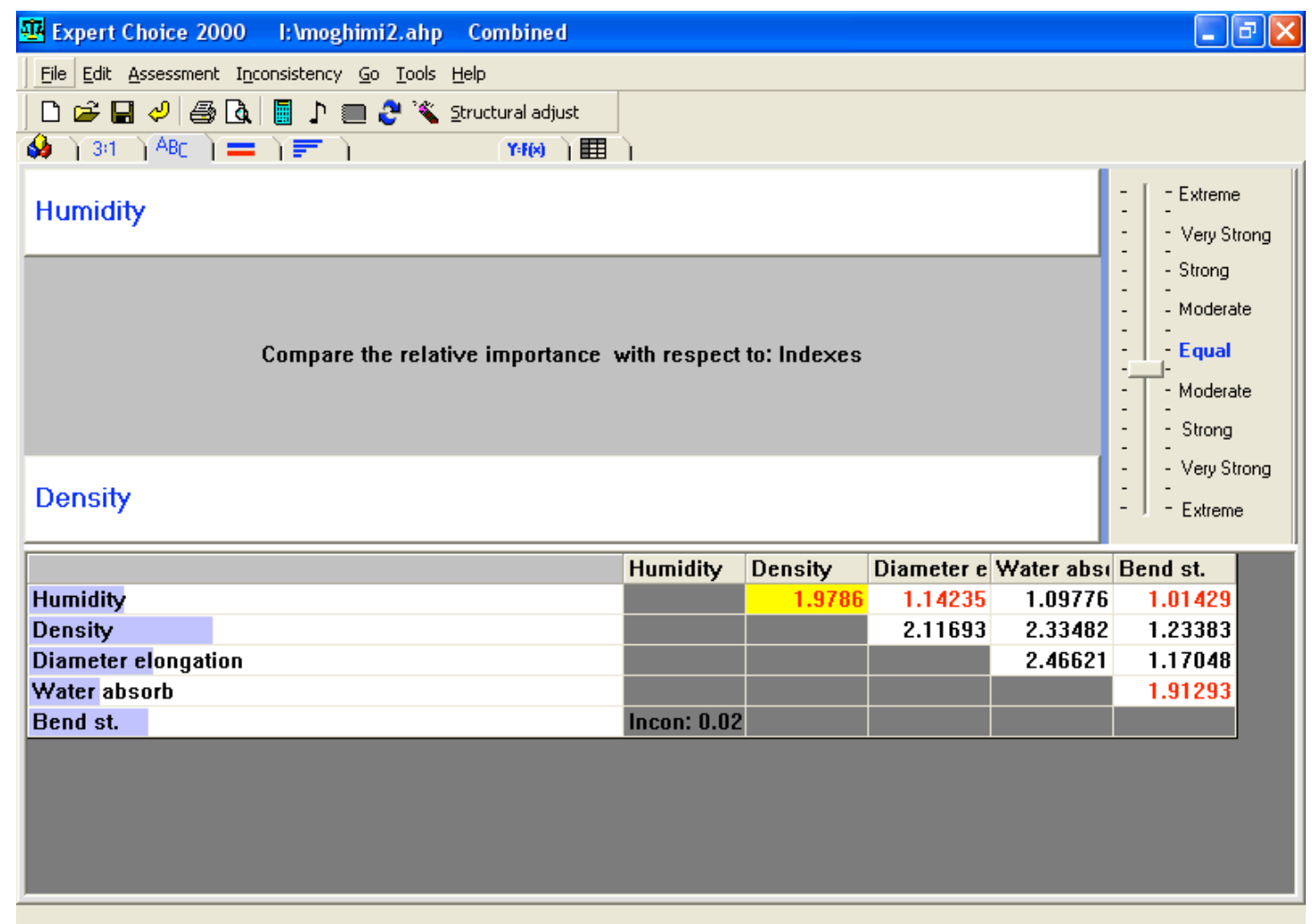

Figure2: Compare the relative importance with respect to goal

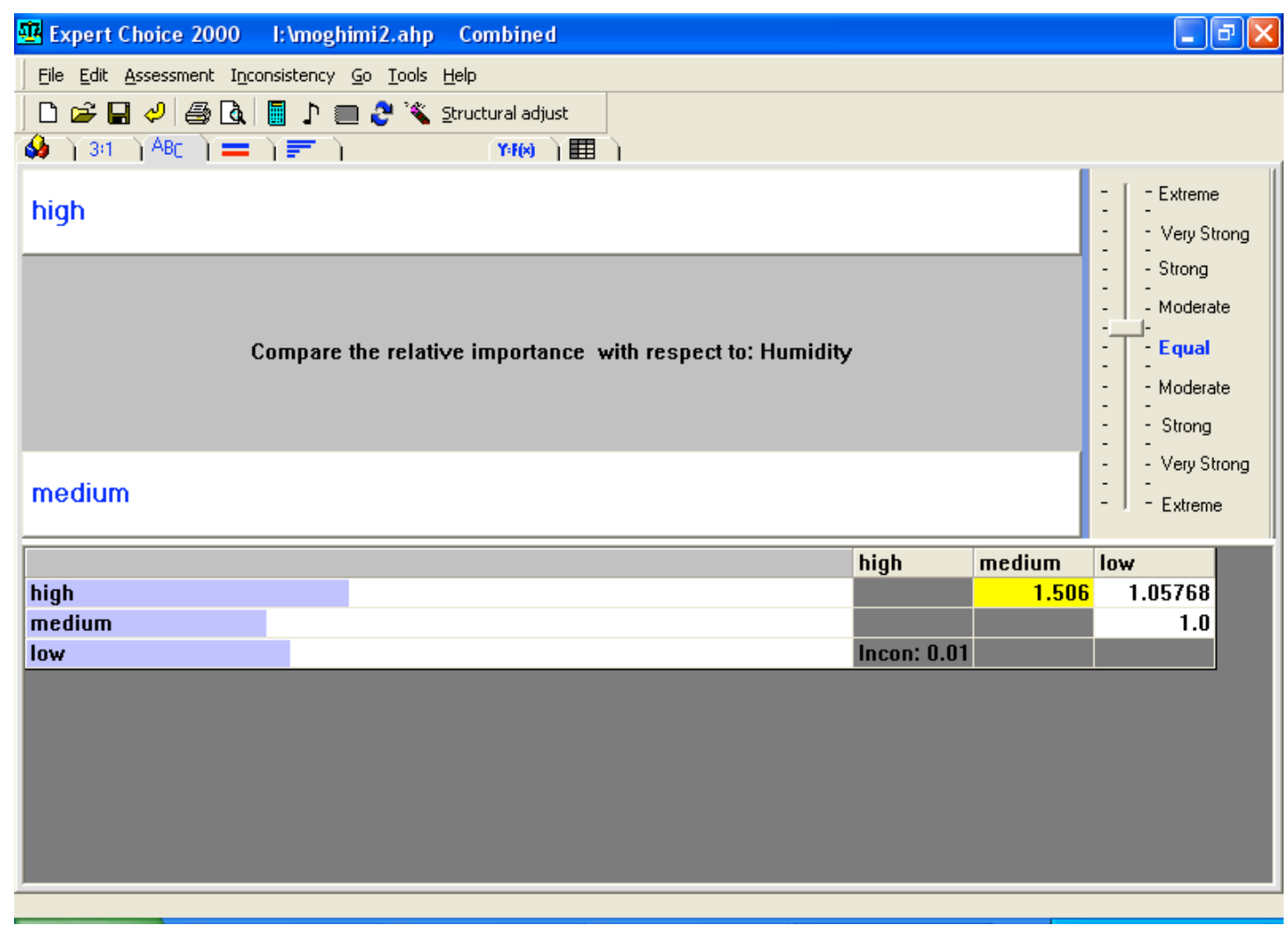


Figure 3: Compare the relative importance with respect to the humidity

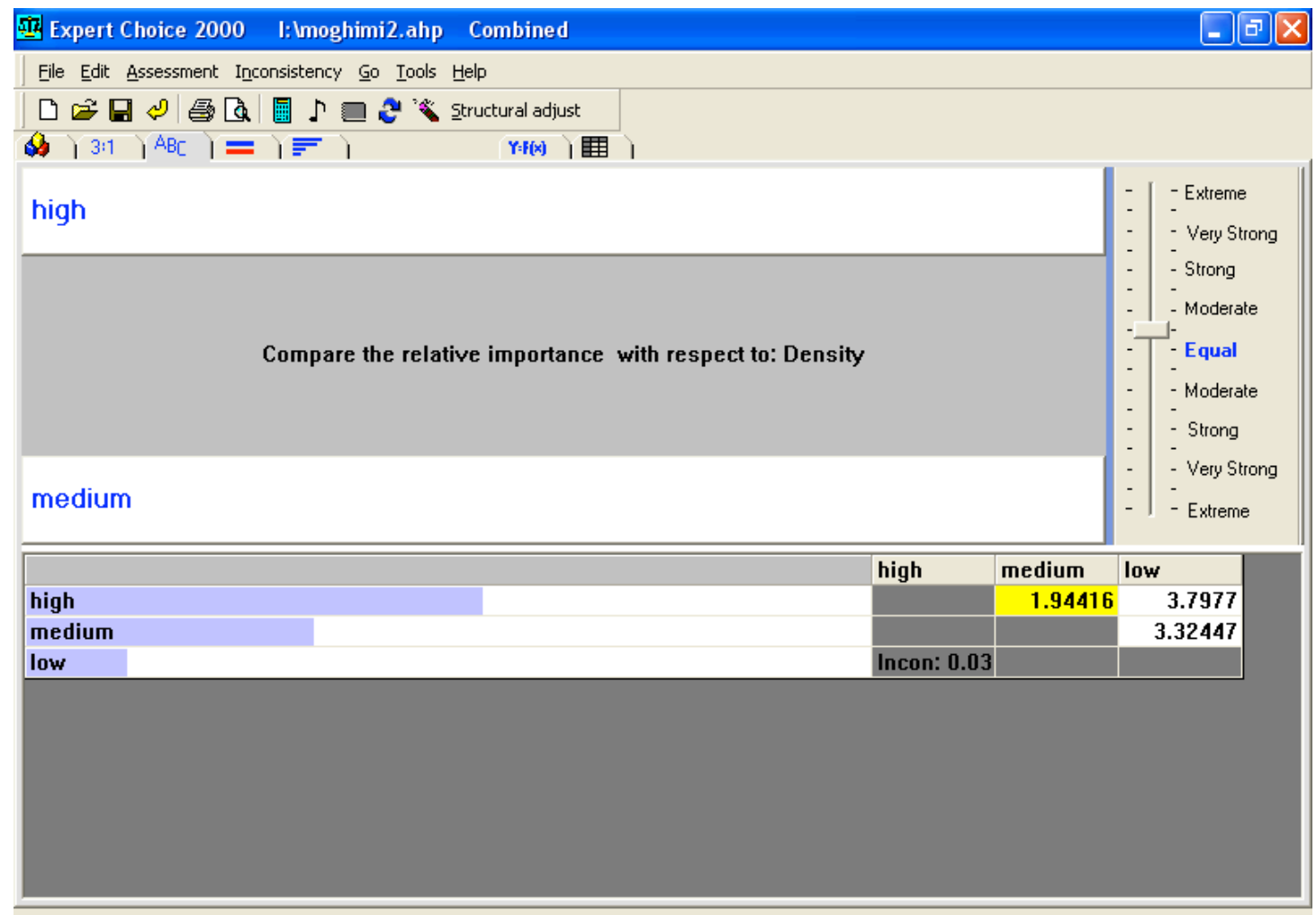

Figure 4: Compare the relative importance with respect to the density 


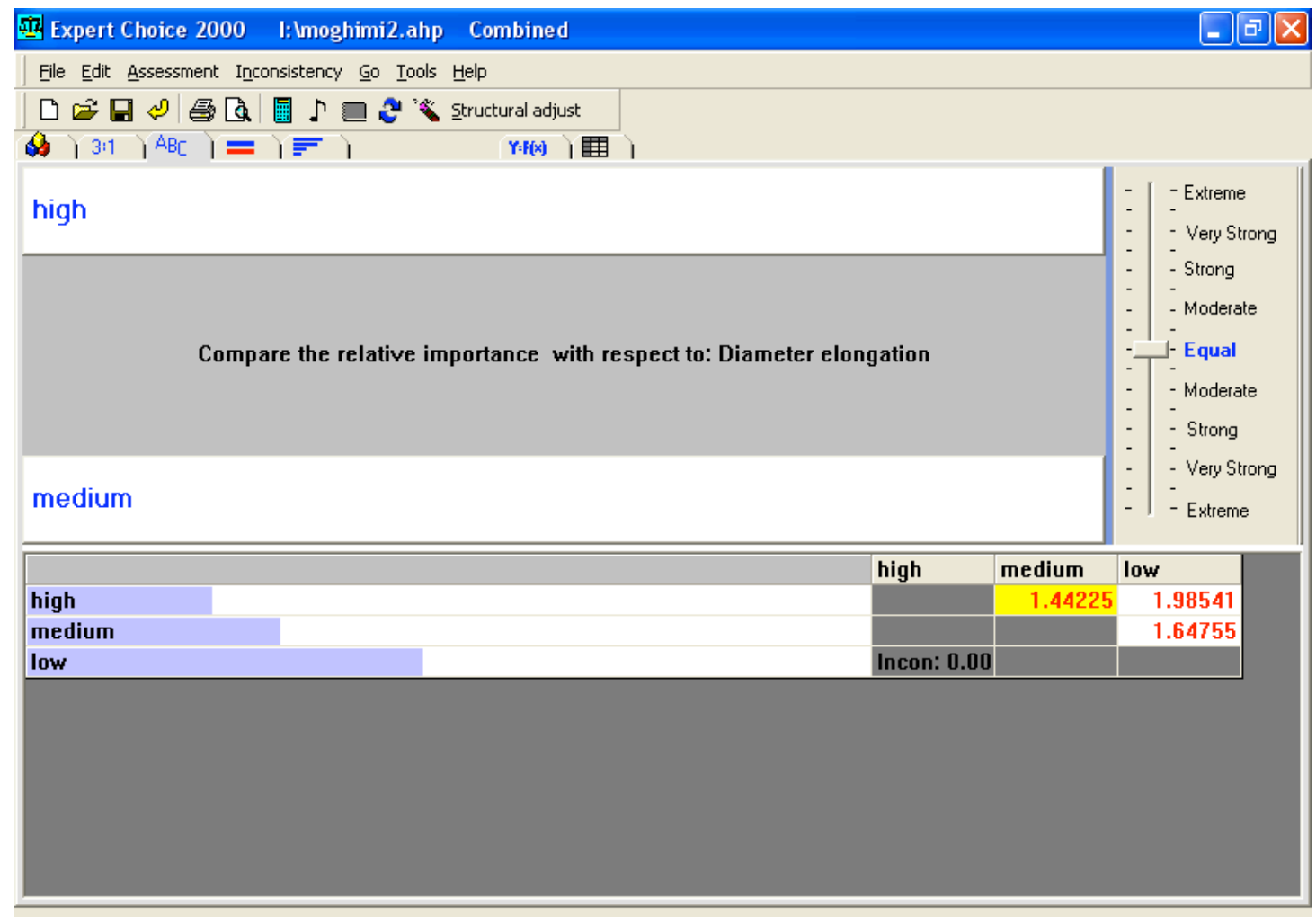

Figure 5: Compare the relative importance with respect to the Thickness swilling

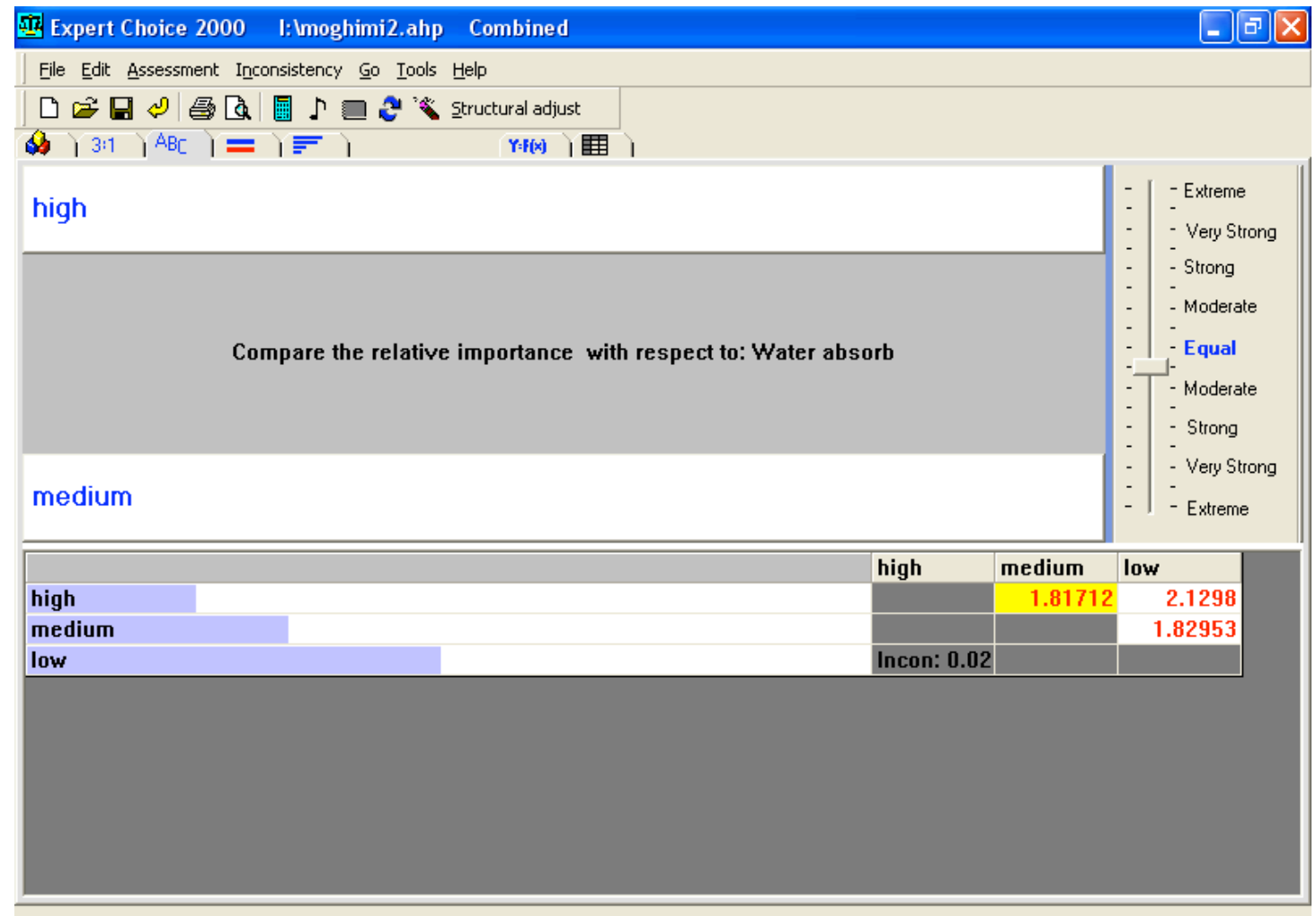

Figure 6: Compare the relative importance with respect to the water absorption 


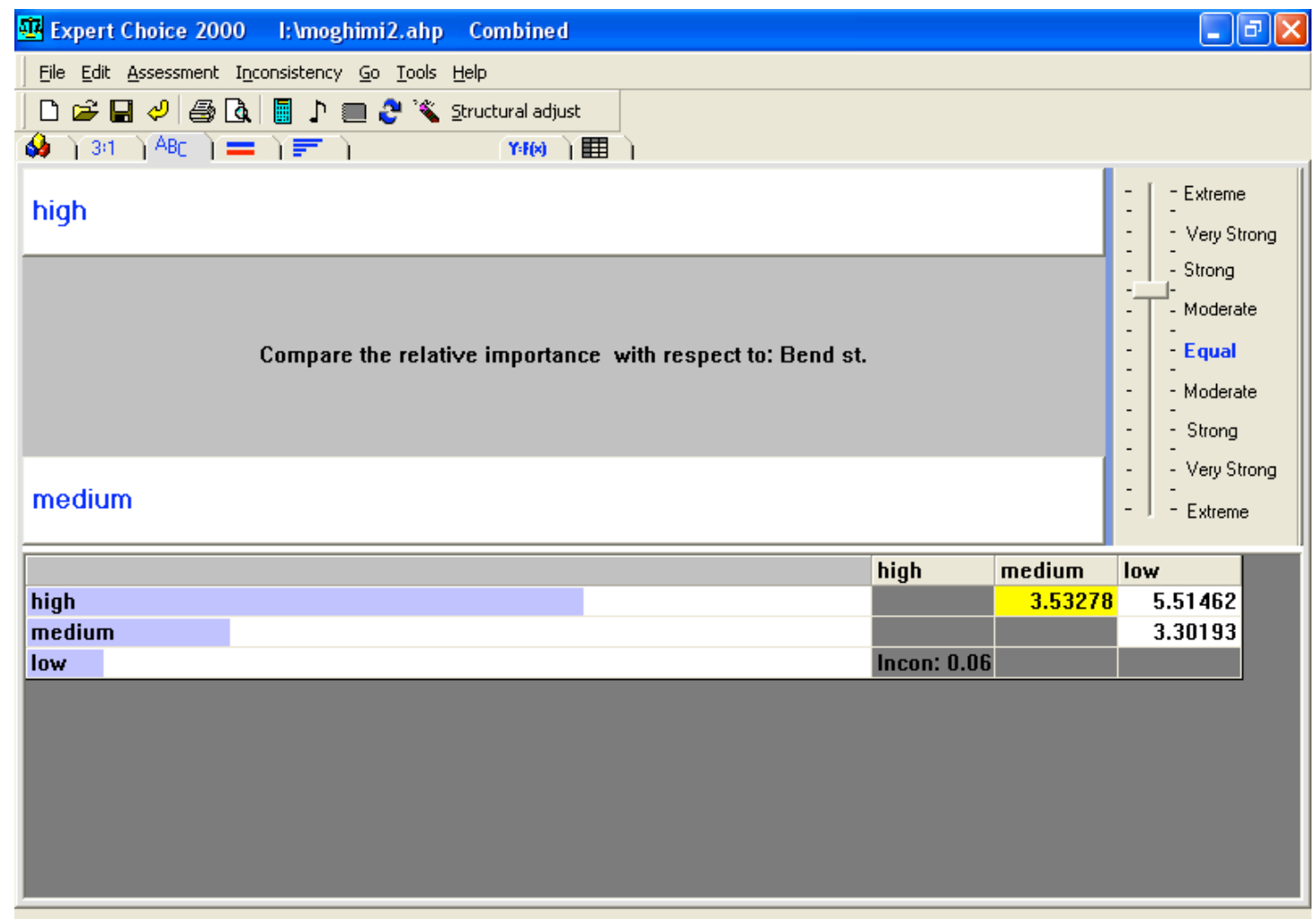

Figure 7: Compare the relative importance with respect to the bending strength

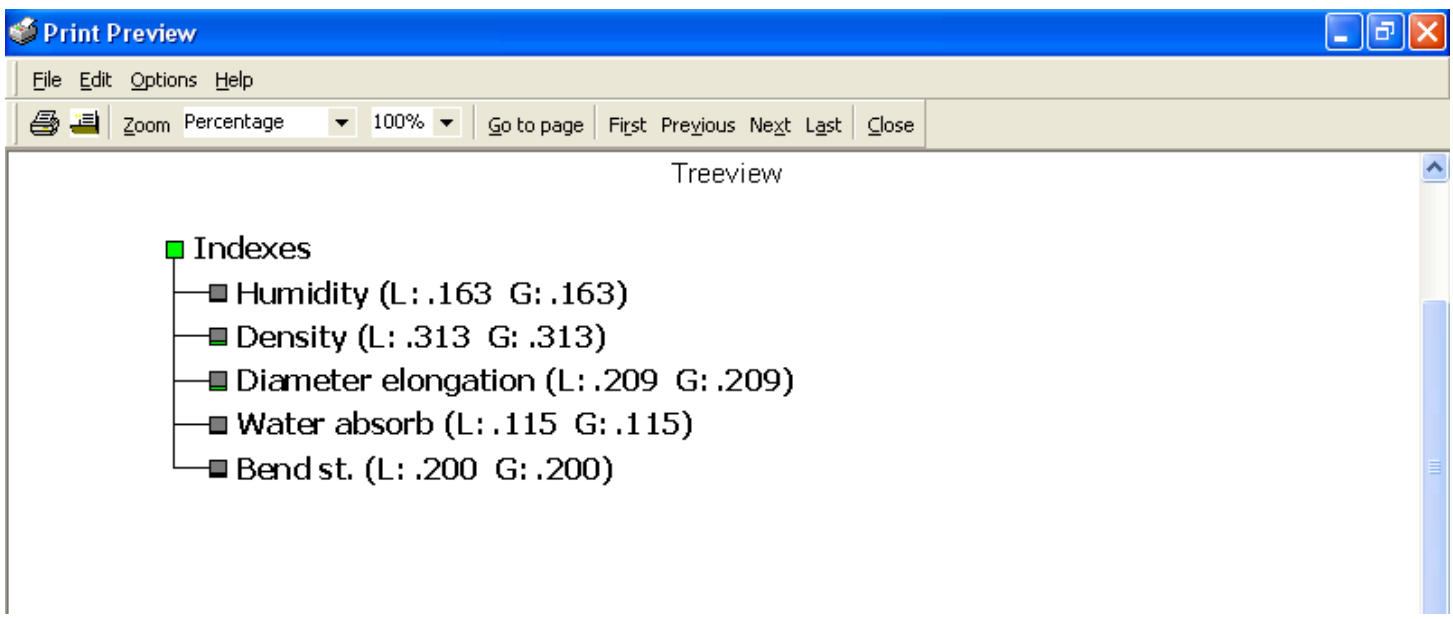

Figure 8: Result of comparison with respect to the goal 


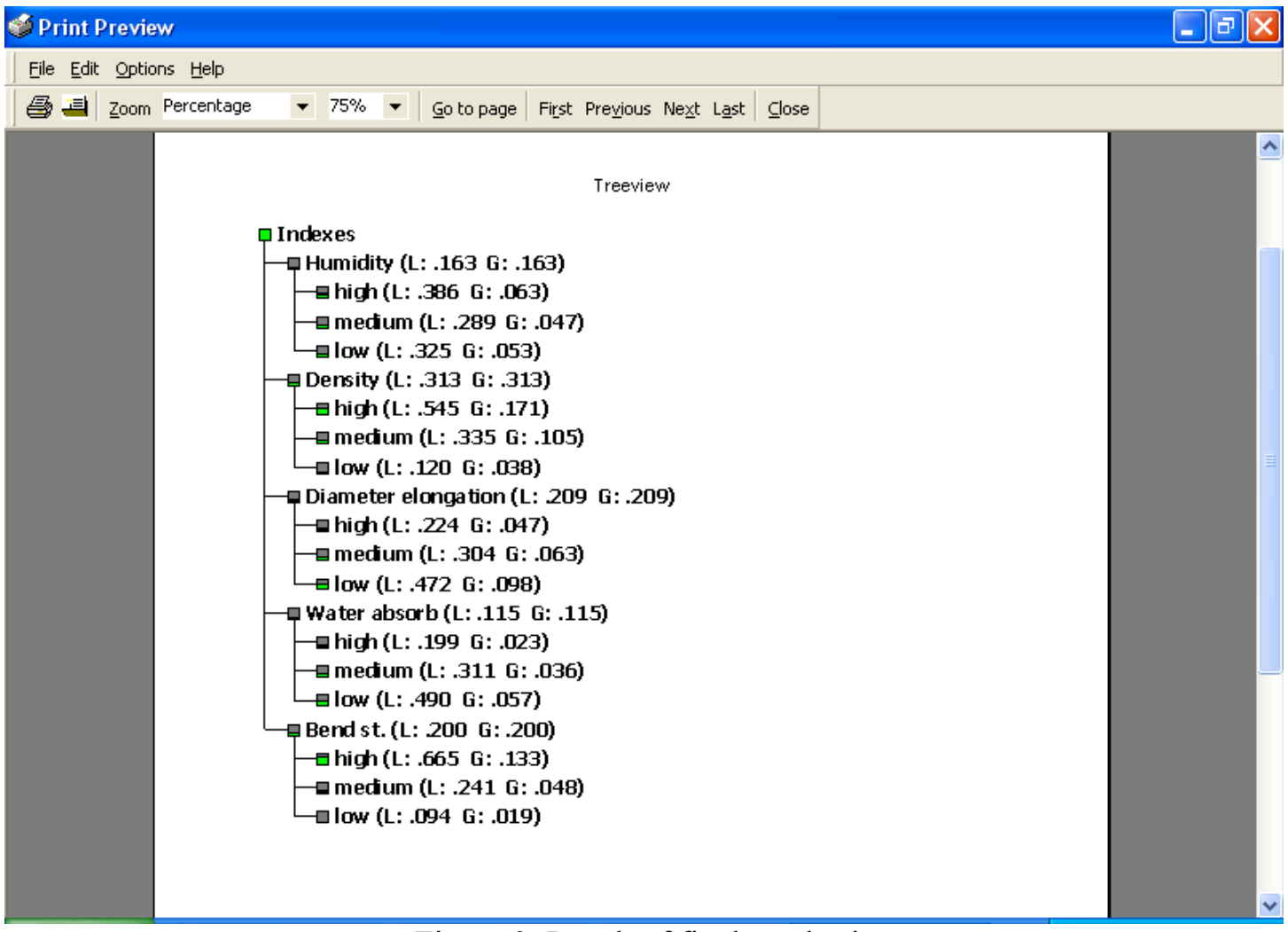

Figure 9: Result of final synthesis

Table 1: Specification of particleboard criteria

\begin{tabular}{|l|l|l|}
\hline Criteria & Standard range & Overall range \\
\hline Humidity $(\%)$ & $6-8$ & $6-8$ \\
\hline Density $\left(\mathrm{g} / \mathrm{cm}^{3}\right)$ & $0.6-0.8$ & $0.6-0.8$ \\
\hline Thickness swilling $(\%)$ & 12 & $6.65-23$ \\
\hline Water absorption $(\%)$ & 50 & $25-75$ \\
\hline Bending strength $\left(\mathrm{kg} / \mathrm{cm}^{2}\right)$ & 160 & $160-210$ \\
\hline
\end{tabular}

\section{Discussion and conclusion}

\subsection{First step: Analysis of criteria priorities}

With respect to t Figure9, density, has 0.313 weighing value which is the highest priority for the particleboard and overall consistency ratio of the current research is 0.02 . Density of the product is one of the major criterions which have influences on water absorption, dimension swilling, bending resistance and internal adhesive. Also the producers trend to produce high intensity density of particleboard in comparison with other intensities (figure 9). Thickness swilling has the second priority (0.209), (figure 9). Value of thickness swilling of the board specified after 2 hour in floating which is special for using of particleboard. In the markets, particleboard products which have high thickness swilling percent are inappropriate boards and indicate undesirable production situation with regard to raw material density and press conditions. Bending strength of particleboard has third priority $(0.200)$, otherwise, the boards which have desirable production situation with respect to raw material and press condition, will have high bending strength. In particleboard bending strength have high sensitivity. The 
humidity percent has forth priority (0.163); it depends on press temperature, dryer conditions and environment humidity. Humidity of the particleboard has to check up after press and dryer, because humidity of the board influences on density, bending strength, color and so on. Water absorption percent has least priority $(0.115)$ in comparison with other criteria. With respect to standard measurements, the boards are floating, during of the test, but there is not similar situation in case of furniture and construction panels as well as water absorption impressed by density, press condition, glue and additive material.

\subsection{Second step: Analysis of criteria intensities}

Humidity intensities: the range of humidity percent is 6-8 percent (table1). With respect to the results humidity percent with high intensity (0.063) (figure 9) has highest priority. High intensity humidity is favorable factor which is positive and increase bending strength and density of the board.

Density intensities: density with high intensity (0.171) (figure 9) has highest priority. Deference of high and low intensities of density is high and it influences the quality and specification of particleboard in distinctive range, which is confirmed by standard organization. With respect to production condition density intensity influences the other specification of the board.

Thickness swilling intensities: low intensity of thickness swilling is considered (0.098) (figure 9). Deference of high and low intensities of thickness swilling is high too. High and low intensities of thickness swilling are $23 \%$ and $6.65 \%$ respectively (table 1 ), with respect to standard organization results, which are confirmed deference of low and high intensities in current research, also the market trends to supply low intensity of thickness swilling for particleboard.

Water absorption intensities: low intensity of water absorption with 0.057 weighing value in comparison with high intensity (0.023) is considerably (figure 9). With respect to standard organization results high and low intensities of water absorption are $75 \%$ and $25 \%$ respectively (table1), high deference of high and low intensities indicate significance of the intensities deference in the particleboard. Water absorption criterion has lowest priority in comparison with other criteria, but range of intensities variation is very effective in particleboard specification.

Bending strength intensities: High intensity of bending strength has 0.133 weighing value with highest priority (figure 9). Deference of high and low intensities for bending strength is very high which indicates

this criterion is very sensitive in particleboard products, otherwise, in the market, particleboard with low intensity of bending strength $\left(160 \mathrm{~kg} / \mathrm{cm}^{2}\right)$ in comparison with high intensity of bending strength $\left(210 \mathrm{~kg} / \mathrm{cm}^{2}\right)$ (table1)has not advantage, according to the producers. Desirability of the boards is increased with high intensity of bending strength but other criteria of the boards have to not decrease due to it, otherwise, it needs economic feasibility.

\section{REFERENCES}

Asgharpoor, M.J. (1999). Multi-criteria decision making. Tehran University, Tehran, 398 p.

Azizi, M. (2008). Non development criteria for particleboard industry. OR 50 conference, University of York, United Kingdom 
Azizi, M., Amiri. S., \& Faezipour, M. (2003). Using AHP method to determine effective criteria for plywood and veneer units location (case study Iran), Journal of the institute of wood science, Vol. 16, Num. 3, Issue. 93.

Azizi, M. (2007). Determination of effective criteria in Iranian facial tissue industries with respect to customer's perspective, ISAHP 2007, Vina Del Mar, Valparaiso, Chile

Cellulose and packaging research group, (2002). Properties and test methods, No. 2496, Institute of standards and industrial research of Iran.

Chen, E. W., \& Li, H. (2001). An approach to determine measures for business performance, Measuring Business Excellence, 3

Saaty, T.L. (2000). Decision making for leaders, RWA Publications, Pittsburg, PA. 